\title{
Fluctuating asymmetry in the honey bee, Apis mellifera: effects of ploidy and hybridization
}

\author{
D. R. Smith, ${ }^{1,2}$ B. J. Crespi ${ }^{1.3}$ and F. L. Bookstein ${ }^{4}$ \\ 'Museum of Zoology, University of Michigan, Ann Arbor, MI 48109, USA \\ ${ }^{2}$ Current address: Department of Entomology, Haworth Hall, University of Kansas, \\ Lawrence, KS 66045, USA \\ ${ }^{3}$ Current address: Department of Biological Sciences, Simon Fraser University, \\ Burnaby V5A 156, British Columbia, Canada \\ ${ }^{4}$ Institute of Gerontology, University of Michigan, Ann Arbor, MI 48109, USA
}

Key words: Fluctuating asymmetry; Apis mellifera; mtDNA; allozymes; Procrustes methods.

\begin{abstract}
We present a new measure of morphological asymmetry that avoids most of the statistical problems inherent in character-by-character analysis of size or shape. The method is an application of Procrustes analysis, which computes best-fitting superpositions of configurations of landmarks to the left and right sides of a single specimen. The Procrustes method combines subtle deviations in all aspects of the landmark configuration into one net asymmetry score. Directional asymmetry is separated from fluctuating asymmetry in a simple partition of a net sum-of-squares, and geometrical details of either component can be inspected by traditional methods of multivariate statistical analysis of landmarks.

We demonstrate this method in a comparison of wing venation asymmetry in male (haploid) and female (diploid) honey bees (Apis mellifera). In addition we investigate the effects of ploidy and inter-subspecies hybridization on asymmetry and wing venation abnormalities, using the subspecies $A . m$. mellifera, $A . m$. carnica, and the hybrid strain "Nigra". Results suggest that while the haploid males showed a higher frequency of wing venation abnormalities and greater total asymmetry than the diploid females, most of the asymmetry difference between males and females was in the form of directional, not fluctuating, asymmetry. Hybrid females had a higher frequency of wing venation abnormalities than females of either subspecies, but there were no significant differences in the mean level of asymmetry among females of $A . m$. mellifera, $A . m$. carnica and hybrid Nigra.
\end{abstract}


Hybrid males had higher absolute frequency of wing venation abnormalities and asymmetry than males of either subspecies. However the mean frequency of venation abnormalities did not differ significantly between Nigra and $A$. $m$. carnica males, and mean asymmetries were not significantly different between Nigra and $A$. m. mellifera males. We discuss the relationship which is assumed to exist between developmental stability and fluctuating asymmetry in light of our results.

Palmer and Strobeck (1986) review methods for the analysis of asymmetry in one dimension at a time: linear distances between homologous points. We argue here that the Procrustes method, which computes the best-fitting superpositions of configurations of landmarks (Gower, 1975; Goodall, 1991; Siegel and Benson, 1982; Rohlf and Slice, 1990; Rohlf and Bookstein, 1990), is a more appropriate measure of morphological asymmetry in two dimensions. This technique derives its name from the story of Procrustes, a villain of Greek mythology.

"Procrustes, or the Stretcher ... had an iron bedstead, on which he used to tie all travellers who fell into his hands. If they were shorter than the bed, he stretched their limbs to make them fit; if they were longer than the bed he lopped off a portion." (Bulfinch, 1991; see also Geisel and Geisel, 1960)." Our method is less painful, but continues to avoid most of the statistical problems inherent in coordinate analysis of shape and size variation.

There are three forms of biological asymmetry: 1) fluctuating asymmetry, in which the character difference between left and right sides of bilateral individuals is distributed normally with mean zero; 2 ) directional asymmetry, in which the mean character value is greater on average for one side; and 3) antisymmetry, in which the character difference distribution is platykurtic or bimodal about mean zero (Palmer and Strobeck, 1986). Fluctuating asymmetry is often assumed to be negatively correlated with developmental stability: since both the genotype and the gross external environment are usually considered to be the same for the left and right sides of a developing organism, all deviations from perfect bilateral symmetry in the fluctuating case should be the result of accidental perturbations of developmental pathways (reviewed in Palmer and Strobeck, 1986). Many studies have noted a decrease in asymmetry with increasing heterozygosity (e.g., Brückner, 1976; Leary et al., 1983, 1984, 1985; McKenzie and Clarke, 1988; Vrijenhoek and Lehrman, 1982; Wayne et al., 1986). Lerner (1954) suggested that heterozygosity increases developmental stability, and thus decreases fluctuating asymmetry. His prediction is supported by associations between fluctuating asymmetry and several correlates and measures of genomic heterozygosity, including inbreeding levels (e.g., Brückner, 1976; Wayne et al., 1986), ploidy (Brückner, 1976; Casteel and Phillips, 1903; Leary et al., 1985), sexual or asexual systems (Vrijenhoek and Lehrman, 1982; Leary et al., 1985) and proportion of scored allozyme loci that are heterozygous (Leary et al., 1983). It is not clear from these studies if the important feature is heterozygosity at specific loci or overall level of heterozygosity throughout the individual's genome. In addition, the developmental mechanisms whereby interactions within and among loci affect asymmetry are unclear (but see MacKenzie and Clarke, 1988). 
Hybridization between individuals from different species, subspecies or genetically differentiated populations has also been associated with an increase in fluctuating asymmetry, even though such hybridization is certain to result in heterozygosity at many loci. Several studies show increased asymmetry in recent hybrid populations (e.g., Ross and Robertson, 1990; Graham and Felley, 1985; Ferguson, 1986; Lamb and Avise, 1987; but see Jackson 1973). These cases are explained by hypothesizing disruption of co-adapted gene complexes and a concomitant decrease in developmental stability.

Because previous studies have analyzed the effects of heterozygosity, ploidy and hybridization on asymmetry separately, their relative importance and the interactions among them cannot be assessed. The honey bee, Apis mellifera, presents an opportunity to analyze the effects of both ploidy and hybridization because the sexes differ in ploidy and because recent hybrid populations can be recognized. Apis mellifera is divided into 24 geographic races or subspecies (Ruttner, 1988), which are interfertile but which are distinguished by morphological (Alpatov, 1929; Ruttner, 1968, 1988; Cornuet et al., 1975; Ruttner et al., 1978), behavioral and ecological (Adam, 1951, 1954, 1961, 1964, 1977; Ruttner, 1988) and biochemical genetic characters (e.g., Cornuet et al., 1986; Sheppard and Berlocher, 1984, 1985; Sheppard and McPheron, 1986; Sylvester, 1982). Females (queens and workers) are diploid, normal males (drones) are haploid. Thus, the effects of ploidy can be investigated by contrasting males and females within a subspecies or population; the effects of hybridization can be investigated by comparing same-sex individuals of pure subspecies and inter-subspecies hybrids. In this study we measured asymmetry in forewing venation and the frequency of forewing venation abnormalities in workers and drones of two subspecies, A.m. mellifera and A.m. carnica, and in the "Nigra" strain, a population which originated through hybridization of these two subspecies.

There have been several earlier studies of asymmetry in Hymenoptera. In Polistes exclamens (Eickwort, 1969) and Bombus rufocinctus (Owen, 1989) haploid males are more variable than diploid females in the distances between selected wing vein intersections. These studies indicate that haploidy is associated with higher frequency of abnormalities and asymmetry, and imply that some aspect of diploidy confers increased developmental stability. Ross and Robertson (1990) compared the effects of interspecific hybridization and heterozygosity on levels of fluctuating asymmetry and wing venation abnormality in alate females of the fire ants Solcnopsis invicta, $S$, richteri and their hybrids. $\Lambda$ symmetry and abnormality were higher in $S$. richteri than in the more heterozygous $S$. invicta. However the hybrid populations exhibited the highest level of asymmetry even though they also had high levels of heterozygosity.

Three studies of asymmetry in honey bees are especially relevant to this work. Casteel and Phillips (1903) showed that forewing venation abnormalities were more common in male honey bees than in females. (Interestingly, this study was carried out in the light of recently rediscovered Mendelian genetics, or 'germinal variation". The authors' working hypothesis was that females would be more variable than males, since the diploid females carry two, potentially different, copies of the 
hereditary material.) Two studies took advantage of the haplo-diploid sex-determining system in honey bees to evaluate the effects of ploidy and inbreeding. Brückner (1976) measured asymmetry in the length of forewing vein segments (segments 16-17 and 17-18 in our Fig. 1) and the number of hamuli on the hind wings of inbred and non-inbred worker and drone honey bees. She showed that asymmetry was higher among drones than among females. In addition Brückner's (1976) results indicated that asymmetry was higher among females from inbred lines than among females from non-inbred lines. This supports the hypothesis that heterozygosity has an effect on asymmetry (and by implication, developmental stability) beyond that conferred by diploidy alone. Brückner (1976) also found that asymmetry and venation variability in females responded differently to inbreeding and concluded that they are independent phenomena. On the other hand, Clarke et al. (1992) also compared asymmetry in haploid male and diploid worker honey bees from inbred and non-inbred families, using the same characters as Brückner (1976). As in the other studies, these authors found males in all families to be more asymmetric than worker females from the same families. However, they found no significant relationship between asymmetry and inbreeding level. The different results in these two studies are not explained by differences in statistical technique, since the discrepancy remained after Clarke et al. (1992) reanalyzed Brückner's (1976) data set using their own methods. One possible source of the discrepancy between the two studies is the degree of inter-subspecies hybridization that had already taken place in the populations analyzed. Brückner (1976) used European $A$. m. carnica; Clarke et al. (1992) used bees from Australia (which may be hybrids of several European races) and North American bees called "A.m. carnica" - though populations of pure subspecies are difficult to document in the Americas.

If we accept the assumption, implicit in all these studies, that fluctuating asymmetry and morphological abnormalities both reflect reduced developmental stability, we may draw the following conclusions: (1) diploids have greater develop-

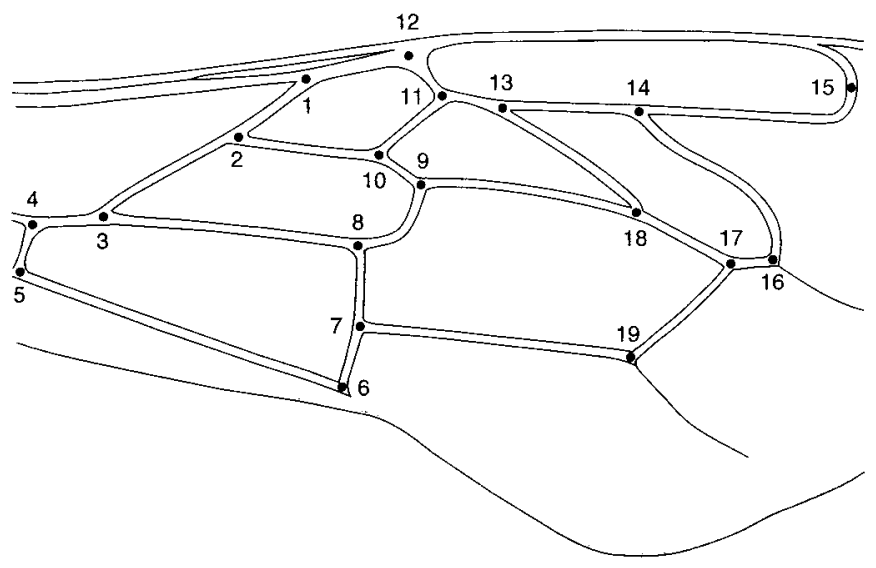

Fig. 1. Digitized points 1 through 19 on fore wing of Apis mellifera. 
mental stability than haploids (Casteel and Phillips, 1903; Brückner, 1976; Eickwort, 1969; Owen, 1989); (2) among diploids, higher heterozygosity is often (but not always) associated with increased developmental stability (Brückner, 1976; Ross and Robertson, 1990); (3) interspecific hybridization decreases developmental stability despite the concomitant increase in heterozygosity (Ross and Robertson, 1990); and (4) asymmetry and abnormalities may have independent developmental causes (Brückner, 1976; Ross and Robertson, 1990).

On the basis of these studies we predict: (1) within any one population of honey bees, the magnitude of fluctuating asymmetry will be greater and wing venation abnormalities will be more frequent in haploid males than diploid females; (2) for each sex, fluctuating asymmetry will be greater and wing venation abnormalities will be more frequent in the hybrid Nigra than in A. m. mellifera or A. m. carnica; and in addition, (3) ploidy and hybridization may interact in their influence on asymmetry and wing venation abnormality, so that the magnitude of any observed hybridization effect might differ between the two sexes.

\section{Methods}

\section{Background}

The range of the honey bee subspecies $A$. m. mellifera originally included most of Europe north of the Alps and the Pyrences, from the British Isles as far east as the Ural mountains (Ruttner, 1988). A. m. carnica is native to southeastern Europe, including parts of Austria, the Balkan peninsula and Hungary (Ruttner, 1988). $A$. $m$. carnica is preferred over $A . m$. mellifera by commercial and hobby bee-keepers. As a result it has been imported extensively into the range of mellifera and in some areas (particularly Germany, Switzerland and northern Austria) has largely replaced mellifera in domesticated populations. Swiss and Austrian "Nigra" bees originated as hybrids of native mellifera, and imported carnica. Subsequently (in Austria beginning in the late 1930's and more intensively after 1956; Ruttner, pers. comm.), some breeders attempted to produce a Nigra population similar to mellifera by selecting on a small number of morphological characters, primarily wing venation (cubital index) and hair length.

The cubital index $(\mathrm{CI})$, or ratio of the length of segment $17-18$ to segment $16-17$ of the forewing cubital vein (Fig. 1), is one of the morphological characters that distinguishes A. m. mellifera and carnica: $\mathrm{CI}=1.84$ (s.d. 0.28) in mellifera workers, 2.59 (s.d. 0.42) in carnica workers (Ruttner 1988; sample sizes not stated). A. m. mellifera and carnica differ in allele frequencies at the cytoplasmic malate dehydrogenase (MDH1) and malic enzyme (MF) loci. Populations of mellifera are characterized by high frequency $(0.85-1.0)$ of the $M d h 1^{80}$ or "medium" allele (Cornuet et al., 1986; Sheppard and Berlocher, 1984) and by the presence of $M e^{79}$ in addition to the more common $\mathrm{Me}^{100}$ (Sheppard and Berlocher, 1984). Populations of carnica have low frequencies of the $M d h 1^{80}$ allele and the $M e^{79}$ allele appears to be absent (Sheppard and McPheron, 1986). A. m. mellifera is also characterized by a set of 
mitochondrial DNA (mtDNA) restriction site and length polymorphisms which is distinct from that of carnica (Smith, 1988; Smith and Brown, 1990; Smith et al., 1989).

\section{Collections}

Fifty to 200 adult worker becs and up to 20 drones were collected from each hive sampled. The drones and 25 to 30 workers were preserved in $90 \%$ ethanol for morphological study. The remaining workers were frozen in liquid nitrogen and transported to the Laboratory for Molecular Systematics, Museum of Zoology, University of Michigan and stored at $-80^{\circ} \mathrm{C}$. Collections of $A$. m. mellifera were made in Laesø, Denmark; Billingstad, Norway; and Uppsala, Sweden. Samples of A. m. carnica are from Graz, Villach and Vienna (Austria); Medvode (Slovenia, formerly Yugoslavia); and Split (Croatia, formerly Yugoslavia). Samples of the honey bee strain "Nigra" were from Ötztalbanhof, Austria. Collections were made in July (carnica and Nigra) and August (mellifera) of 1987.

\section{Genetic data}

In order to demonstrate that our honey bee samples are indeed taken from populations of the subspecies $A . m$. mellifera, A. m. carnica, and the hybrid Nigra strain, we scored allozyme polymorphisms, mtDNA haplotypes, and cubital index in bees from each hive sampled.

Allozymes. Ten workers from each hive (if available) were surveyed for their biochemical phenotypes for cytoplasmic malate dehydrogenase (MDH1 EC 1.1.1.37) and malic enzyme (ME, EC 1.1.1.40) using the methods described in Hagen et al. (1988) and Richardson et al. (1986).

Mitochondrial DNA. Mitochondrial DNA was prepared from the frozen thoraces of 15-25 adult worker bees from each hive following the methods in Smith and Brown (1990), and surveyed for restriction site polymorphisms with 15 six-base restriction enzymes: AccI, AvaI, BclI, BglII, EcoO109, EcoRI, EcoRV, HindII, HindIII, NdeI, PstI, PvuII, SpeI, XbaI and XhoI. On the basis of the restriction fragments generated by these enzymes, the mtDNA of each hive was characterized as typical of mellifera or carnica (Smith and Brown, 1990).

\section{Morphological data}

The left and right wings were removed from ten workers and five drones (if available) from each hive, and mounted in Euparol on glass microscope slides. A set of 38 landmarks ( 19 on each wing) formed by the intersection of wing veins or by the extremities of closed wing vein cells (Fig. 1) were digitized on each forewing. This was accomplished using a video digitizing system (Fink, 1987) consisting of a 


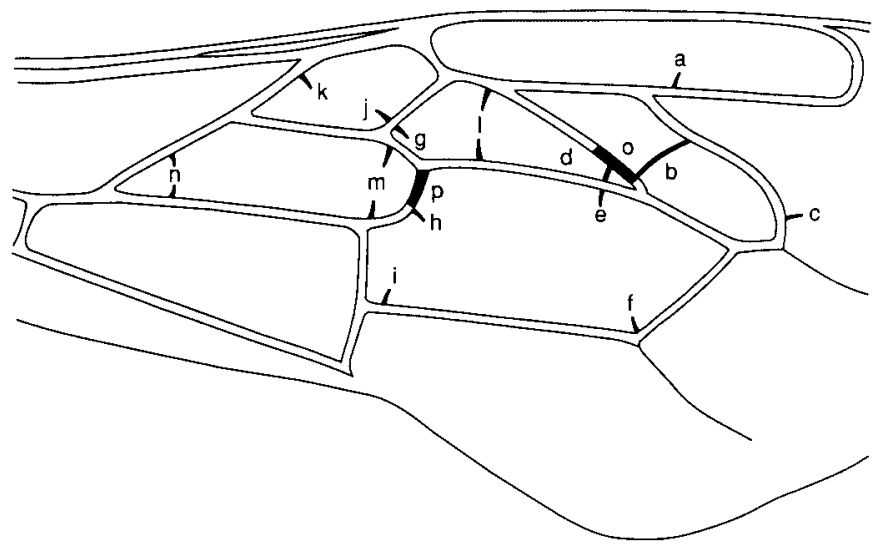

Fig. 2. Venation abnormalities on the fore wing of Apis mellifera. Abnormalities a through $n$ are additional veins, $o$ and $p$ are lost veins (shown in black), and $l, m$, and $n$ are each two spurs of varying length which sometimes meet to form a closed cell.

video camera and monitor, video digitizer, microcomputer and "mouse" driven cursor, and the METRIC software package (B. J. Vernia, University of Michigan). We calculated cubital index for each bee and the mean cubital index for each hive. We also counted the number of common venation abnormalities (shown in Fig. 2) on each forewing and the mean number of abnormalities per individual worker or drone for each hive.

\section{Procrustes analysis of asymmetry}

Over the past ten years, a consensus has emerged regarding multivariate biometric analysis of the shapes of sets of labelled points, such as the sets of wing venation landmarks here. Briefly, for most biometric studies of the shapes of landmark configurations, it is an appropriate first step to compute the Procrustes-average shape and then express sample shape variation for multivariate purposes (though not necessarily for reporting) by the Procrustes residuals of the sample forms as fitted to the average shape. These crucial Procrustes maneuvers will be defined presently. The geometry of these residuals and the ways in which they capture shape variation are now quite well understood (Goodall, 1991); in particular, they capture the same multivariate space of shape variation as do the two-form shape coordinates that were the main concern of Bookstein (1991), and they are an orthogonal rotation of the partial warps of the spline approach, which has likewisc proved quite helpful in recent applications. These Procrustes residuals can be compared across groups or passed to principal-component analysis, linear models, searches for regionalized patterns, and the like. Whenever statistical findings emerge, they can be reported in a strongly visual fashion by geometrically exact diagrams back in the original geometry of the specimen. The theorems on which this consensus is ultimately based were the topic of a recent international meeting of statisticians (Mardia and Gill, 1995), but our experience in their applications to 
routine questions of evolutionary and developmental biology began much earlier; see, for instance, the papers collected in Marcus et al., 1993, 1996. Articles showing general applications of this approach include Bookstein (1995a, b, 1996a, b).

The specialized analysis we shall demonstrate below produces a measure of asymmetry, $A^{2}$, for each specimen (i.e., each wing pair) and then shows how, across samples larger than a single specimen, the mean $A^{2}$ can be decomposed into one term for fluctuating asymmetry and another term for directional asymmetry. The first appearance of these developments in book form (Bookstein, 1991) includes a brief discussion of these bee wings using a slightly different algorithm for the computations. Bookstein (1996b) likewise includes a brief discussion of asymmetry; in the same volume is a worked example involving the rodent skull (Auffray et al., 1996).

A Procrustes procedure for asymmetry studies begins, as do all other algorithms of this class, with the two-point Procrustes fit (Fig. 3). Throughout this paper, we will be considering forms that should be "the same": specifically, all right wings have been mirrored before analysis to look like the left wings. Thus, a single specimen is represented by a pair of similar landmark shapes, such as the four-landmark example in Fig. 3A. The two-form Procrustes fit proceeds in three steps. First, the centroid of each form is computed as the ordinary average of the Cartesian coordinate pairs of all its landmark points (Fig. 3B). (The square root of this sum of squares is the quantity usually called centroid size in modern morphometrics.) Next each form is rescaled so that in each the sum of the squared distances of the landmarks from their centroid is equal to one. Then the centroids are superposed (Fig. 3C) and one form is rotated relative to the other until the sum of squared distances between corresponding landmarks is a minimum over all such rotations. In Fig. 3D, the distances between corresponding landmarks are shown as vectors. If the $k$ landmark locations after the centering and scaling steps are written out for both forms as $x_{i j}, y_{i j}, i=1,2, j=1, \ldots, k$, then the angle of rotation for fitting the first form atop the second is

$$
\arctan \frac{\sum\left(x_{1 j} x_{2 j}+y_{1 j} y_{2 j}\right)}{\sum\left(x_{1 j} y_{2 j}-x_{2 j} y_{1 j}\right)}
$$

counterclockwise. Other algorithms that arrive at the same result are available in Rohlf (1990), Rohlf and Slice (1990), and Bookstein (1991).

The most convenient measure of asymmetry is the sum of squares of those vectors, which is proportional to the total area of circles in the lower right hand diagram of Figure 3. We call this the squared Procrustes distance, or $A^{2}$. The units of $A$ are thus the units of Procrustes distance, which are dimensionless; this same unit corresponds to the scales of all of the scatterplots and diagrams here. The superposition just introduced is actually the one that minimizes this value $A^{2}$. Formally, $A$ is a standard error of prediction and $A^{2}$ is an unexplained variance $\left(1-r^{2}\right)$ in a "univariate" regression of one set of landmarks upon the other after both are normalized to a variance (or Centroid Size) of I (Bookstein, 1996b, reviews in Mardia and Gill, 1995). This regression approach is taken further in Bookstein 1991, where the quantities reported are taken about wing-specific means rather than a grand mean, and so are about $10 \%$ smaller than the values reported here. 
This procedure can be generalized to studies of more than one form or specimen at a time (see Rohlf and Slice, 1990). Once we fit each of a sample of forms to a reference form, for example, the first form of the data set, we can average the fitted coordinates, then re-fit all the original specimens to this average, re-average the fits, and so on. The cycle converges very quickly to the Procrustes average shape for the sample of forms, shown in the left panel of Figure 4 by the open triangles. (This is also the shape that has least summed squared Procrustes distance to all the original shapes of the sample, just as the ordinary average of a set of numbers is the value that has the least summed squared difference from all of them taken as a set.) In the panel at the right of Figure 4 - in which construction lines are deleted - the whole

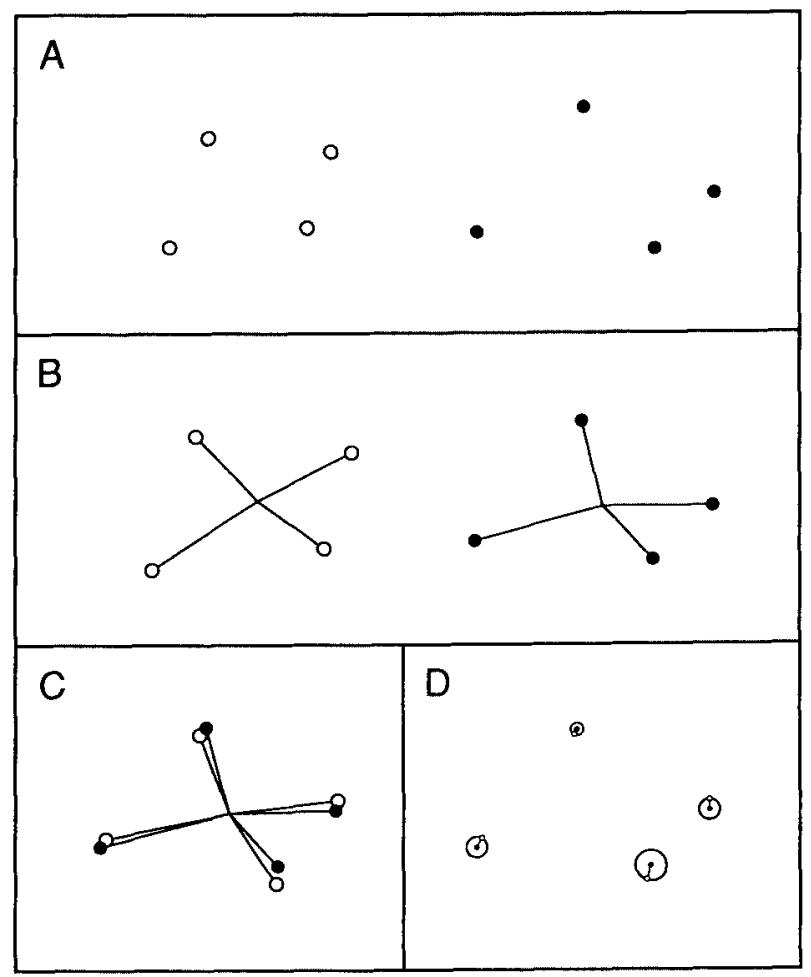

Fig. 3. Example of a Procrustes superposition of a left and right set of landmarks. (A) Simulated left and mirrored right wing of one bee, each with four landmarks (left wing, open circles; mirrored right wing, solid circles). The asymmetry shown here is enormously larger than anything encountered in our data. (B) Each form is resealed so that the sum of squares of the distances to the centroid of its four landmarks is 1 . This is the sum of squares of the four lines shown. (C) The centroids of the left and right wings are superimposed, and one form is then rotated relative to the other so that the sum of squared distances between corresponding landmarks is a minimum. (D) With the construction lines erased, the asymmetry, $A^{2}$, of this pair of wings is the sum of squared distances between corresponding landmarks. It is proportional to the total area of the circles whose radii are the distances between corresponding landmarks. 


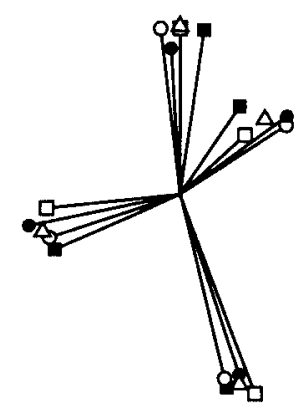

Four forms centered, scaled, rotated

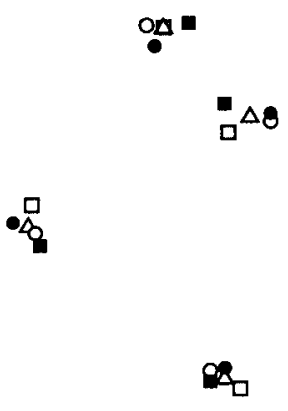

Procrustes fit coordinates

Fig. 4. Computation of Procrustes average shape. (A) Emergence of an average form (open triangles) from the alternation of two-form supcrpositions (Fig. 1) with averages of the resulting superposed locations. (B) Resulting sample scatter of linearized shapes. This scatter is the initial set-up for multivariate statistics of group mean shape comparisons, correlations with morphogens, etc. (see Bookstein, 1996b). Open and solid squares: right wings of two individuals. Open and solid circles: left wings of two individuals. Triangles, Procrustes average shape for four landmarks on two wings of two individuals.

sample of shapes is displayed as a collection of the residuals. The average size and the total size of the scatters, as estimated from their visible extent on the page, are a useful guide to the magnitude of Procrustes distances among samples and between left and right wings.

Mean squares of $A$ (that is, means of $A^{2}$ ) will be written $\overline{\mathbf{A}^{2}}$. "Raw" asymmetries $(A)$ will be computed as $\sqrt{ } A^{2}$. There is thus a difference between the squares of mean asymmetries, $\overline{\mathbf{A}}$ (as in Tabs. 2 through 4 ) and mean-squared asymmetries, $\overline{\mathbf{A}^{2}}$ (Tab. 5).

When both wings are plotted on the same plane of shape variation, the decomposition of $A^{2}$ into directional and fluctuating asymmetry - on which our analysis centers - is the graphical equivalent of a nested analysis of variance, side within specimen, as shown in Figure 5. The example here shows the left and right wings of two bees (Fig. 5A). The directional component of asymmetry is the sum of squared distances from mean left-wing location of landmarks to mean right-wing location of landmarks: the sum of squared lengths of the vectors shown in Fig. 5B. The remaining component of the mean squared asymmetry is fluctuating asymmetry. This is the sum of squared differences between vectors connecting each specimen's paired landmarks (shown by vectors in Fig. 5C) and their own averages, which delineate the mean shape differences between left and right wings. This is not the sum of squares of the vectors in $5 \mathrm{C}$, but their variance about the mean vectors shown in 5B. In other words, the sum of the squared lengths of the vectors in Figure $5 \mathrm{C}$ divides into two components, one corresponding to the sum of squares of the vectors in Fig. 5B, which are their averages, and the other representing the sum of squares around these averages. The former part is directional asymmetry, the latter, fluctuating asymmetry. 
In this example the amount of shape change shown, whether within or between specimens, is far greater than any actually found in our sample of bee wings. Had we drawn this geometry realistically, none of the vectors of interest would have been legible at the scales shown in Figures 3-5.

\section{Results}

\section{Characterization of populations}

Allele frequencies and cubital indices of our $A . m$. mellifera and $A$. m. carnica samples match published descriptions of these subspecies (Tab. 1). The allozyme, mtDNA and cubital index data also support the claim that the Nigra population we sampled is a hybrid of $A . m$. mellifera and $A . m$. carnica. All three common $M d h I$ alleles are found in the Nigra samples, and mean allele frequencies in the Nigra samples are intermediate between those of $A . m$. mellifera and $A$. m. carnica. Both mellifera and carnica mtDNA are found in this Nigra population, with mellifera mtDNA predominating. The mean value for worker cubital index in the Nigra sample falls between the values for the mellifera and carnica samples, and is significantly different from either (one-way ANOVA with pairwise comparisons: mellifera and Nigra, $F=11.97, p<0.001$; carnica and Nigra, $F=58.16, p<0.0001$ ).
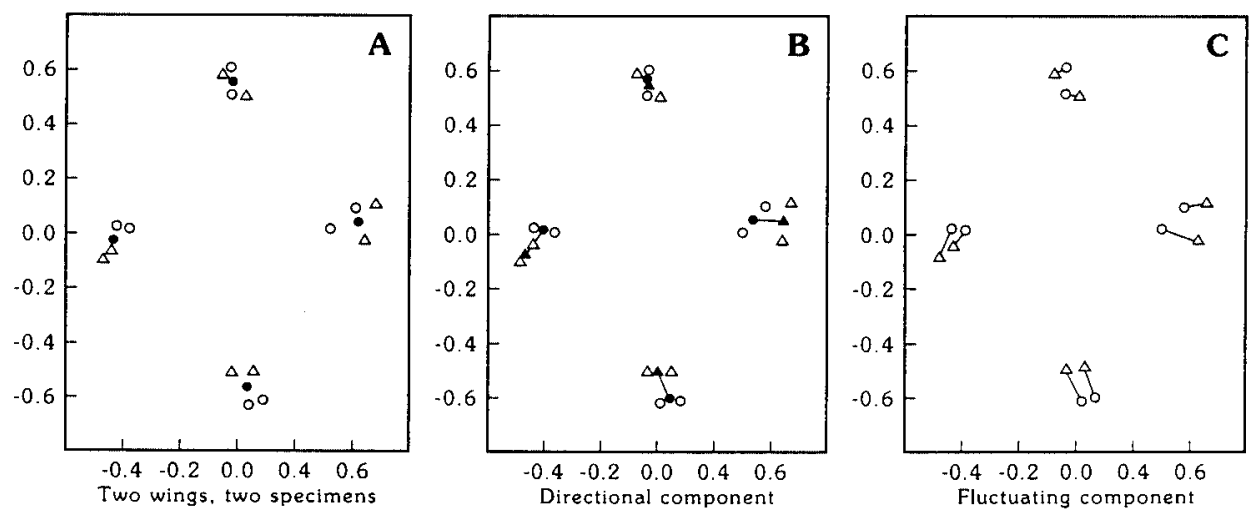

Fig. 5. Schematic of the decomposition of total asymmetry, $A^{2}$, into directional and fluctuating components. Axes are marked in the dimensionless units of Procrustes distance. This example uses left and right wings of two individuals with four landmarks on each wing. Left wing landmark coordinates are shown by open circles, and mirrored right wing landmark coordinates are shown by open triangles. (A) Left wing and right wing landmark coordinates shown as Procrustes superpositions around their grand means (solid dots). (B) The directional component of mean $A^{2}$ is the sum of squared distances between mean left and right wing coordinates. Mean left and right wing coordinates are shown as solid circles and triangles, respectively; distances between them are shown by lines representing vectors. (C) The left-right differences in landmark position for each individual bee are shown by lines representing vectors. The fluctuating component of mean $A^{2}$ is computed as the mean squared variance of the individual left-right ditferences about the mean shape difference vectors shown in $5 \mathrm{~B}$. 
Table 1. Mean $M d h l$ and $M e$ allele frequencies of workers, and mtDNA genotype and mean cubital indices $(\mathrm{CI})$ of workers and drones from hives of $A$. m. mellifera, A. m. carnica and the Austrian Nigra strain. $\mathrm{N}=$ number of bees sampled. MtDNA genotypes in these populations are either mellifera-like (M) or carnica-like (C) (Smith and Brown, 1990). Cubital index is calculated as the ratio of segment 17-18 to segment $16-17$ of the cubital vein (Fig. 1). Nigra and A. m. carnica samples showed only $M e^{10 \%}$; the frequency of $M e^{79}$ in colonies of $A . m$. mellifera were as follows (hive = frequency $(\mathrm{N})$ : $1=0.09(11) ; 2=0.10(10) ; 3=0.44(8) ; 4=0.0(2) ; 5=0.50(10) ; 6=0.56(11) ; 7=0.0(2) ; 8=0.10(11)$; $9=0.0$ (11). $M d h l$ alleles are $M d h^{165}(\mathrm{~S}) ; M d h 1^{80}(\mathrm{M}) ; M d h I^{100}(\mathrm{~F})$; Sheppard and Berlocher, 1984, 1985.

\begin{tabular}{|c|c|c|c|c|c|c|c|c|c|c|}
\hline \multirow[t]{2}{*}{ Hive } & \multirow[t]{2}{*}{ Population } & \multirow[t]{2}{*}{ MtDNA } & \multicolumn{4}{|c|}{ Mdh I allele frequency } & \multicolumn{4}{|c|}{ Cubital index } \\
\hline & & & $\mathrm{S}$ & $\mathrm{M}$ & $F$ & $N$ & Female & $N$ & Male & $\mathrm{N}$ \\
\hline 1 & mellifera & $\mathrm{M}$ & 0.0 & 0.96 & 0.04 & 13 & 1.55 & 10 & 1.34 & 5 \\
\hline 2 & mellifera & $\mathbf{M}$ & 0.0 & 0.90 & 0.10 & 10 & 1.46 & 10 & 1.15 & 4 \\
\hline 3 & mellifera & $\mathrm{M}$ & 0.0 & 0.95 & 0.05 & 10 & 1.66 & 10 & 1.41 & 5 \\
\hline 4 & mellifera & $\mathrm{M}$ & 0.0 & 1.0 & 0.0 & 13 & 1.75 & 10 & 1.49 & 4 \\
\hline 5 & mellifera & $\mathrm{M}$ & 0.03 & 0.97 & 0.0 & 16 & 1.44 & 10 & 1.32 & 6 \\
\hline 6 & mellifera & $\mathrm{M}$ & 0.0 & 1.0 & 0.0 & 11 & 1.65 & 10 & 1.49 & 5 \\
\hline 7 & mellifera & $\mathrm{M}$ & 0.0 & 1.0 & 0.0 & 13 & 1.66 & 10 & 1.58 & 4 \\
\hline 8 & mellifera & $\mathrm{M}$ & 0.17 & 0.83 & 0.0 & 15 & 1.73 & 10 & 1.17 & 4 \\
\hline 9 & mellifera & $\mathrm{M}$ & 0.0 & 0.91 & 0.09 & 11 & 1.67 & 10 & 1.30 & 1 \\
\hline \multicolumn{2}{|c|}{$\begin{array}{l}\text { Mean for mellifera: } \\
\text { (Standard deviation): }\end{array}$} & & 0.02 & 0.95 & 0.03 & & $\begin{array}{r}1.62 \\
(0.25)\end{array}$ & 90 & $\begin{array}{r}1.36 \\
(0.21)\end{array}$ & 38 \\
\hline 10 & Nigra & $\mathrm{M}$ & 0.50 & 0.0 & 0.50 & 1 & 1.92 & 10 & 1.23 & 5 \\
\hline 11 & Nigra & $\mathrm{M}$ & - & - & - & 0 & 2.11 & 7 & 1.54 & 5 \\
\hline 12 & Nigra & $\mathrm{C}$ & 0.80 & 0.15 & 0.05 & 10 & 2.67 & 10 & 2.06 & 5 \\
\hline 13 & Nigra & $\mathrm{M}$ & 0.71 & 0.19 & 0.10 & 21 & 1.76 & 9 & 1.01 & 5 \\
\hline 14 & Nigra & $\mathrm{M}$ & 0.15 & 0.80 & 0.05 & 10 & 1.19 & 10 & 1.17 & 5 \\
\hline 15 & Nigra & $\mathrm{M}$ & 0.35 & 0.25 & 0.40 & 10 & 1.46 & 10 & 1.41 & 5 \\
\hline 16 & Nigra & $\mathrm{C}$ & 0.90 & 0.0 & 0.10 & 10 & 2.60 & 10 & 1.93 & 5 \\
\hline 17 & Nigra & $\mathrm{M}$ & 0.35 & 0.35 & 0.30 & 10 & 1.78 & 10 & 1.31 & 4 \\
\hline 18 & Nigra & $\mathrm{M}$ & 0.10 & 0.75 & 0.10 & 10 & 1.34 & 10 & 1.02 & 3 \\
\hline \multirow{2}{*}{\multicolumn{2}{|c|}{$\begin{array}{l}\text { Mean for all Nigra: } \\
\text { (Standard deviation): } \\
\text { Mean for Nigra with } \\
\text { mellifera-like mtDN } \Lambda \text { : } \\
\text { (Standard deviation): }\end{array}$}} & : & 0.48 & 0.31 & 0.20 & & $\begin{array}{c}1.86 \\
(0.59)\end{array}$ & 86 & $\begin{array}{c}1.43 \\
(0.45)\end{array}$ & 41 \\
\hline & & & & & & & $\begin{array}{c}1.63 \\
(0.41)\end{array}$ & 66 & $\begin{array}{c}1.25 \\
(0.35)\end{array}$ & 31 \\
\hline 19 & carnica & $\mathrm{C}$ & 0.28 & 0.0 & 0.72 & 18 & 2.62 & 9 & & 0 \\
\hline 20 & carnica & $\mathrm{C}$ & 0.75 & 0.0 & 0.25 & 10 & 2.88 & 10 & 1.83 & 5 \\
\hline 21 & carnica & $\mathrm{C}$ & 0.61 & 0.0 & 0.39 & 14 & 2.44 & 10 & 2.08 & 5 \\
\hline 22 & carnica & $\mathrm{C}$ & 0.75 & 0.0 & 0.25 & 20 & 2.46 & 10 & 2.08 & 5 \\
\hline 23 & camica & $\mathrm{C}$ & 0.60 & 0.40 & 0.10 & 10 & 2.32 & 10 & 1.84 & 5 \\
\hline 24 & camica & $\mathrm{C}$ & 0.42 & 0.0 & 0.58 & 12 & 2.30 & 9 & 1.60 & 5 \\
\hline 25 & carnica & $\mathrm{C}$ & 0.58 & 0.0 & 0.42 & 12 & 2.02 & 10 & 2.14 & 4 \\
\hline 26 & carnica & $\mathrm{C}$ & 0.72 & 0.25 & 0.03 & 16 & 2.45 & 8 & 2.11 & 5 \\
\hline 27 & carnica & $\mathrm{C}$ & 0.62 & 0.0 & 0.38 & 12 & 2.24 & 9 & 1.43 & 5 \\
\hline \multicolumn{2}{|c|}{$\begin{array}{l}\text { Mean for carnica: } \\
\text { (Standard deviation): }\end{array}$} & & 0.59 & 0.07 & 0.33 & & $\begin{array}{c}2.41 \\
(0.51)\end{array}$ & 85 & $\begin{array}{c}1.88 \\
(0.42)\end{array}$ & 39 \\
\hline
\end{tabular}


However, if the two Nigra colonies with carnica mtDNA are omitted, the mean worker cubital index of the remaining Nigra hives is not significantly different from the mean for the mellifera sample $(F=0.31, p<0.861)$.

\section{Asymmetry and venation abnormalities}

Table 2 presents the mean values of total asymmetry and mean number of wing venation abnormalities per individual in males and females of A. m. mellifera, A. m. carnica and Nigra. Tables 3 and 4 present these results in more detail, giving mean values per hive and standard deviations. Our average asymmetry measure, $\overline{\mathbf{A}_{\mathbf{i}}^{2}}$, for the 377 bees in our sample is 0.000729 , representing a "typical" residual deviation of left from right landmark, after the regression fit, of 0.0062 .

The subdivision of this averaged asymmetry into fluctuating and direct components is approximately 50:50. Figure 6 shows, magnified fourfold, the mean shape difference between left and right wings. The squared Procrustes length of this difference is 0.000361 . The remainder of the mean square asymmetry $A^{2}$, as in the right-hand panel of Figure 5, is variation around this mean shape difference. This is shown in Figure 7, which draws all the left-right asymmetries as if they were multiple right wings facing one single left wing. The sample mean square of fluctuating asymmetry is the total variance of the 19 scatters in this plot: that total is $0.000729-0.000361=0.000368$. Recall that this is the average squared length of 377 vectors each of 38 Cartesian coordinates.

It is useful to compare these mean squares to analogous quantities for sample variation of wing shape itself over the entire collection of subspecies and sexes. Figure 8, the equivalent of Figure 4 for all 377 left wings, shows that in general these scatters are directional, not circular, and that the net variation of one wing across the sample is quite a bit larger than the net variation between wings within specimens. That is, wings from different individuals differ more, on average, than left and right wings of the same individual. In fact, the mean squared variation in Figure 8 - that is, the Procrustes diameter of this sample of left wings - is 0.00121 , more than three times the average squared left-right distance within single speci-

Table 2. Mean asymmetry and mean wing venation abnormalities in diploid female workers and male drones of $A$. m. mellifera, A. m. carnica and the Nigra strain.

\begin{tabular}{|c|c|c|c|c|c|c|}
\hline \multirow[t]{2}{*}{ Population } & \multicolumn{3}{|c|}{ Females (diploid) } & \multicolumn{3}{|c|}{ Mates (haploid) } \\
\hline & $\begin{array}{l}\text { Mean } \\
\text { asymmetry }\end{array}$ & $\begin{array}{l}\text { Mean No. } \\
\text { abnormalities }\end{array}$ & $\mathrm{N}$ & $\begin{array}{l}\text { Mean } \\
\text { asymmetry }\end{array}$ & $\begin{array}{l}\text { Mean No. } \\
\text { abnormalities }\end{array}$ & $\mathrm{N}$ \\
\hline mellifera & 0.0245 & 0.20 & 90 & 0.0310 & 0.55 & 37 \\
\hline Nigra & 0.0251 & 0.72 & 86 & 0.0322 & 1.48 & 48 \\
\hline carnica & 0.0247 & 0.36 & 85 & 0.0279 & 1.41 & 38 \\
\hline All & 0.0248 & 0.42 & 261 & 0.0304 & 1.16 & 116 \\
\hline
\end{tabular}


Table 3. Mean asymmetry and mean wing venation abnormalities in worker females of $A$. m. mellifera, A. $m$. carnica and the Nigra strain. $\mathrm{N}=$ sample size for asymmetry data.

\begin{tabular}{|c|c|c|c|c|c|c|}
\hline Hive & Population & $\begin{array}{l}\text { Mean } \\
\text { asymmetry }\end{array}$ & s.d. & $\begin{array}{l}\text { Mean } \# \\
\text { abnormalities }\end{array}$ & s.d. & $\mathrm{N}$ \\
\hline 1 & mellifera & 0.0236 & 0.0027 & 0.00 & 0.00 & 10 \\
\hline 2 & mellifera & 0.0257 & 0.0049 & 0.00 & 0.00 & 10 \\
\hline 3 & mellifera & $0.02 / 6$ & 0.0016 & 0.20 & 0.42 & 10 \\
\hline 4 & mellifera & 0.0268 & 0.0080 & 0.20 & 0.42 & 10 \\
\hline 5 & mellifera & 0.0227 & 0.0020 & 0.10 & 0.32 & 10 \\
\hline 6 & mellifera & 0.0237 & 0.0037 & 0.10 & 0.32 & 10 \\
\hline 7 & mellifera & 0.0227 & 0.0029 & 0.40 & 0.70 & 10 \\
\hline 8 & mellitera & 0.0252 & 0.0046 & 0.50 & 0.85 & 10 \\
\hline 9 & mellifera & 0.0226 & 0.0036 & 0.30 & 0.48 & 10 \\
\hline \multicolumn{2}{|c|}{ Mean for mellifera: } & 0.0245 & 0.0044 & 0.20 & 0.48 & 90 \\
\hline 10 & Nigra & 0.0239 & 0.0026 & 0.50 & 0.85 & 10 \\
\hline 11 & Nigra & 0.0218 & 0.0039 & 1.14 & 1.46 & 7 \\
\hline 12 & Nigra & 0.0239 & 0.0041 & 0.50 & 0.71 & 10 \\
\hline 13 & Nigra & 0.0239 & 0.0047 & 0.67 & 0.87 & 9 \\
\hline 14 & Nigra & 0.0281 & 0.0054 & 0.90 & 0.99 & 10 \\
\hline 15 & Nigra & 0.0252 & 0.0036 & 1.00 & 0.94 & 10 \\
\hline 16 & Nigra & 0.0260 & 0.0038 & 0.80 & 0.79 & 10 \\
\hline 17 & Nigra & 0.0255 & 0.0049 & 0.10 & 0.32 & 10 \\
\hline 18 & Nigra & 0.0252 & 0.0044 & 1.00 & 0.94 & 10 \\
\hline \multicolumn{2}{|c|}{ Mean for Nigra: } & 0.0261 & 0.0043 & 0.72 & 0.90 & 86 \\
\hline 19 & carnica & 0.0235 & 0.0025 & 0.44 & 1.01 & 9 \\
\hline 20 & carnica & 0.0240 & 0.0028 & 0.30 & 0.67 & 10 \\
\hline 21 & carnica & 0.0238 & 0.0031 & 0.10 & 0.32 & 10 \\
\hline 22 & carnica & 0.0211 & 0.0036 & 1.50 & 1.43 & 10 \\
\hline 23 & cannica & 0.0222 & 0.0031 & 0.20 & 0.42 & 10 \\
\hline 24 & carnica & 0.0287 & 0.0065 & 0.11 & 0.33 & 9 \\
\hline 25 & carnica & 0.0263 & 0.0059 & 0.20 & 0.63 & 10 \\
\hline 26 & carnica & 0.0280 & 0.0049 & 0.375 & 0.52 & 8 \\
\hline 27 & carnica & 0.0260 & 0.0055 & 0.00 & 0.00 & 9 \\
\hline \multirow{2}{*}{\multicolumn{2}{|c|}{$\begin{array}{l}\text { Mean for carnica: } \\
\text { Means for all females: }\end{array}$}} & 0.0247 & 0.0048 & 0.36 & 0.81 & 85 \\
\hline & & 0.0248 & 0.0045 & 0.42 & 0.78 & 261 \\
\hline
\end{tabular}

men. (For the right wings, it is 0.00116 , not significantly different.) This is similar to figures for variation in mosquito wings (Rohlf, 1993). Clearly this structure is under stringent developmental control (at least for those specimens living long enough to be included in our samples).

Effects of ploidy: contrasting males and females

The mean number of wing venation abnormalities per individual was significantly higher in males than in females over all populations (one-way ANOVA, $F=38.84$, $p<0.00 \mathrm{I}$ ) and within each population (one-way ANOVA: mellifera males vs. females, $F=6.17, p<0.014$; Nigra, $F=12.34, p<0.001$; carnica, $F=21.87, p<$ 0.001 ; Tabs. 2,3 and 4 ). 
Across all populations total asymmetry is greater for haploid males than for diploid females (one-way ANOVA, $F=132.10, p<0.001$; Tab. 2). Within each population males also show significantly higher levels of asymmetry than females (one-way ANOVA: mellifera, $F=61.037$; Nigra, $F=82.118$; carnica, $F=12.994$; all $p<0.001$; Tab. 2).

Total asymmetry can be partitioned into its components, directional asymmetry and fluctuating asymmetry (Tab. 5). Our biggest surprise was that most of the symmetry difference between males and females is not due to fluctuating asymmetry, but to directional asymmetry. Total or net asymmetry can be computed for each specimen, but computation of the directional component of asymmetry

Table 4. Mean asymmetry and mean wing venation abnormalities in drones (males) of $A$. m. mellifera, A. $m$. carnica and the Nigra strain.

\begin{tabular}{|c|c|c|c|c|c|c|}
\hline Hive & Population & $\begin{array}{l}\text { Mean } \\
\text { asymmetry }\end{array}$ & s.d. & $\begin{array}{l}\text { Mean \# } \\
\text { abnormalities }\end{array}$ & s.d. & $N$ \\
\hline 1 & mellifera & 0.0337 & 0.0020 & 1.00 & 1.41 & 5 \\
\hline 2 & mellifera & 0.0300 & 0.0033 & 0.00 & 0.00 & 4 \\
\hline 3 & mellifera & 0.0310 & 0.0021 & 0.00 & 0.00 & 5 \\
\hline 4 & mellifera & 0.0300 & 0.0037 & 1.00 & 0.82 & 4 \\
\hline 5 & mellifera & 0.0325 & 0.0022 & 1.67 & 2.07 & 6 \\
\hline 6 & mellifera & 0.0288 & 0.0075 & 0.00 & 0.00 & 5 \\
\hline 7 & mellifera & 0.0304 & 0.0021 & 0.25 & 0.50 & 4 \\
\hline 8 & mellifera & 0.0325 & 0.0032 & 0.25 & 0.50 & 4 \\
\hline 9 & mellifera & 0.0239 & - & 0.00 & - & 1 \\
\hline Mean for & mellifera: & 0.0310 & 0.0038 & 0.55 & 1.13 & 38 \\
\hline 10 & Nigra & 0.0346 & 0.0041 & 1.00 & 1.00 & 5 \\
\hline 11 & Nigra & 0.0314 & 0.0058 & 1.60 & 0.55 & 5 \\
\hline 12 & Nigra & 0.0326 & 0.0024 & 2.60 & 2.88 & 5 \\
\hline 13 & Nigra & 0.0317 & 0.0034 & 0.80 & 1.09 & 5 \\
\hline 14 & Nigra & 0.0293 & 0.0022 & 1.20 & 0.84 & 5 \\
\hline 15 & Nigra & 0.0323 & 0.0044 & 1.00 & 1.00 & 4 \\
\hline 16 & Nigra & 0.0330 & 0.0047 & 2.20 & 2.28 & 5 \\
\hline 17 & Nigra & 0.0349 & 0.0057 & 1.50 & 1.29 & 4 \\
\hline 18 & Nigra & 0.0290 & 0.0029 & 1.33 & 0.58 & 3 \\
\hline Mean for & Nigra: & 0.0322 & 0.0041 & 1.48 & 1.485 & 41 \\
\hline 19 & carnica & - & - & - & - & 0 \\
\hline 20 & camica & 0.0278 & 0.0028 & 1.80 & 1.30 & 2 \\
\hline 21 & carnica & 0.0303 & 0.0065 & 0.60 & 0.89 & 3 \\
\hline 22 & carnica & 0.0276 & 0.0039 & 2.60 & 1.95 & 5 \\
\hline 23 & carnica & 0.0272 & 0.0022 & 1.20 & 1.30 & 5 \\
\hline 24 & carnica & 0.0269 & 0.007 I & 0.60 & 0.89 & 3 \\
\hline 25 & carnica & 0.0248 & 0.0017 & 2.50 & 3.11 & 4 \\
\hline 26 & carnica & 0.0279 & 0.0020 & 1.40 & 1.14 & 5 \\
\hline 27 & camica & 0.0286 & 0.0061 & 0.80 & 1.79 & 5 \\
\hline \multirow{2}{*}{\multicolumn{2}{|c|}{$\begin{array}{l}\text { Mean for carnica: } \\
\text { Mean for all males: }\end{array}$}} & 0.0278 & 0.0035 & 1.41 & 1.65 & 37 \\
\hline & & 0.0304 & 0.0042 & 1.16 & 1.49 & 116 \\
\hline
\end{tabular}




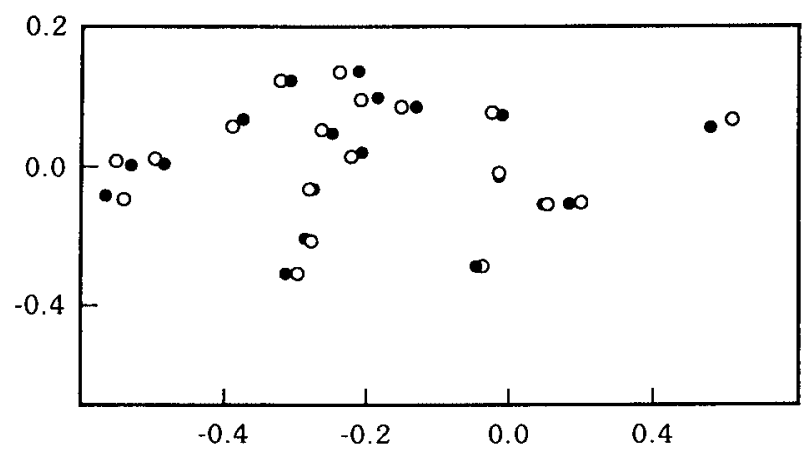

Fig. 6. Mean shape dirferences between left and right wings of all specimens, times 4 . Mcan lcft wing landmark coordinates are shown by open circles, mean right wing landmark coordinates are shown by solid circles. Axes are marked in dimensionless units of Procrustes distance.

requires averaging over samples. Of the mean-square of the asymmetry measure 0.000729 (over all 377 bees), $49 \%$ or 0.000361 is due to directional asymmetry, the measure $A^{2}$ of asymmetry between the sample mean configurations of left and right wings. The remaining half of $\overline{\mathbf{A}^{2}}$ is fluctuating asymmetry. Separately by sex, the amount of directional asymmetry was larger for males $\left(A^{2}=0.00063\right)$ than for females (0.00029), but the mean-squares of fluctuating asymmetry were virtually the same in the two sexes $(0.00034$ for males versus 0.00031 for females). The size of the right wings averaged $101.1 \%$ of the size of the left in the males, but only $100.25 \%$ of the size of the left in the females.

\section{Effects of hybridization: contrasting subspecies and hybrids}

A. m. mellifera, A. m. carnica and Nigra samples differed significantly in mean number of wing venation abnormalities, both for females (one-way ANOVA, $F=11.00, p<0.001)$ and males $(F=4.97, p \sim 0.01)$. Nigra females had higher frequencies of venation abnormalities than $A . m$. mellifera and $A . m$. carnica females (Nigra vs. pooled mellifera and carnica females, Mann-Whitney $\mathbf{U}, p<$ 0.001; Tabs. 2 and 3). Nigra males also had the highest mean frequency of venation

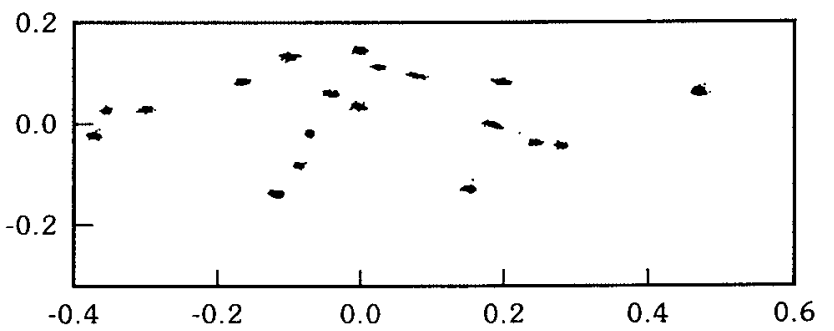

Fig. 7. Net asymmetry in 377 pairs of Apis mellifera wings, left-right differences plotted as displacements from the grand mean left wing shape. Mean squared asymmetry is just about $30 \%$ of the total variability of wing form over the three populations sampled. Axes are marked in dimensionless units of Procrustes distance. 


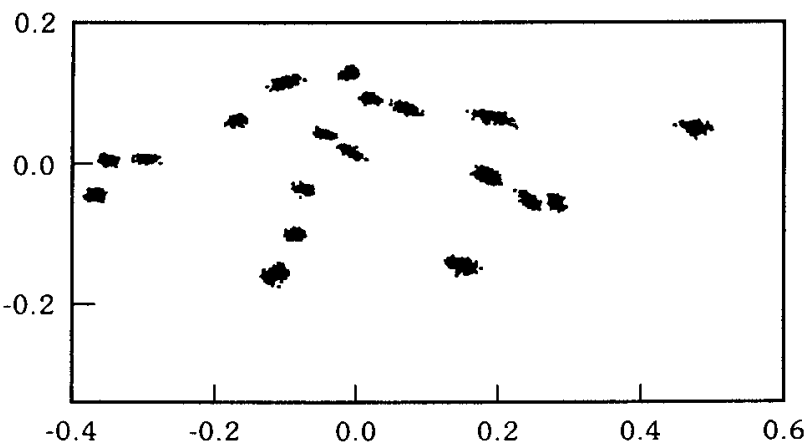

Fig. 8. Net shape variation in 377 left wings of Apis mellifera as shown by Procrustes fits of 19 landmarks. (A plot of reflected right wings is similar.) Notice the relatively small range of sizes of these scatters, especially of their smaller dimension. Axes are marked in dimensionless units of Procrustes distance.

abnormalities (Nigra vs. pooled mellifera and carnica malcs, Mann-Whitney U, $p \sim 0.01$; Tabs. 2 and 4), but the difference between Nigra and carnica males was not significant (Tab. 4).

Asymmetry showed a different pattern. There was no significant difference in mean total asymmetry among $A . m$. mellifera, $A . m$. carnica and Nigra females (one-way ANOVA, $F=0.312, p<0.732$; Tabs. 2 and 3 ). Analysis of variance revealed significant differences in total asymmetry among mellifera, carnica and Nigra males (one-way ANOVA, $F=14.79, p<0.001$; Tabs. 2 and 4). Nigra males had the highest mean asymmetry, but the difference between Nigra and mellifera males was not significant (one-way ANOVA with pairwise comparisons, $F=2.16$, $p<0.144$; Tab. 4).

The subsample of males with the largest mean squared directional asymmetry is the Nigra subpopulation: the value of 0.000748 is more than double the grand mean square of 0.000361 . The geometry of this asymmetry, Figure 9, looks remarkably similar to that in Figure 6, but has been magnified only twofold, not fourfold. Notice, for instance, that the directions of displacement from the dots to the triangles in Figure 9 are usually parallel to those in Figure 6.

Table 5. Partitioning of total squared asymmetry into directional and fluctuating components; all entries $\times 10^{4}$.

\begin{tabular}{lllllll}
\hline $\mathrm{N}$ & $\begin{array}{l}\text { All bees } \\
377\end{array}$ & $\begin{array}{l}\text { All females } \\
261\end{array}$ & $\begin{array}{l}\text { All males } \\
116\end{array}$ & $\begin{array}{l}\text { mellifera males } \\
38\end{array}$ & $\begin{array}{l}\text { Nigra males } \\
41\end{array}$ & $\begin{array}{l}\text { carnica males } \\
37\end{array}$ \\
\hline $\begin{array}{c}\text { Total squared } \\
\text { asymmetry: }\end{array}$ & 7.29 & 6.34 & 9.42 & 9.75 & 10.50 & 7.89 \\
$\begin{array}{c}\text { Directional squared } \\
\text { asymmetry: }\end{array}$ & 3.61 & 2.89 & 6.31 & 7.13 & 7.48 & 5.57 \\
$\begin{array}{c}\text { Fluctuating squared } \\
\text { asymmetry: }\end{array}$ & 3.68 & 3.45 & 3.11 & 2.62 & 3.02 & 2.32 \\
\hline
\end{tabular}




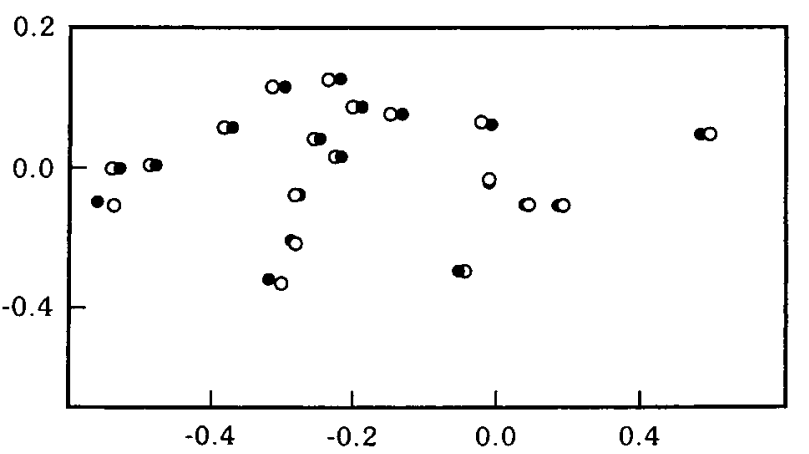

Fig. 9. Directional asymmetry for the most asymmetric Apis mellifera subsample, males of the hybrid Nigra population, magnified twofold. Mean left wing landmark coordinates are shown by open circles, mean right wing landmark coordinates are shown by solid circles. Axes are marked in dimensionless units of Procrustes distance. Compare to Fig. 6.

Fluctuating asymmetry was marginally higher in Nigra males than in males of the two subspecies, but as was the case in the comparison of males and females, most of the difference in asymmetry among males of the three populations was accounted for by differences in directional asymmetry (Tab. 5).

\section{Correlations between abnormalities and asymmetries}

There were no significant correlations between the mean number of wing abnormalities per individual and mean asymmetry in each colony, either among males or females. Correlations between asymmetry and venation abnormalities are similarly low in other comparisons (e.g., among males and females of each population) or vary erratically (e.g., the correlation between asymmetry and venation abnormalities ranges from $0.8808, p<0.0017$ to $-0.6664, p<0.0354$ among females of each colony).

\section{Discussion}

One aspect of developmental stability is buffering against perturbation during development. We, along with other authors, have hypothesized that buffering is influenced by heterozygosity, ploidy, and hybridization. Assuming that fluctuating asymmetry and frequency of morphological abnormalities are measures of buffering ability and developmental stability, what do our results reveal about the usefulness of asymmetry (fluctuating and directional) and frequency of abnormalities as measures of developmental stability?

As expected, haploid males showed a higher frequency of wing venation abnormalities and higher total asymmetry than diploid females, both within populations and overall. Thus, with respect to sex or ploidy, asymmetry and abnormalities behaved the same way. 
The biggest surprise in our results was that most of the difference in asymmetry between males and females was due to directional asymmetry, not fluctuating asymmetry. None of the earlier studies of asymmetry in honey bees (in fact, few studies of fluctuating asymmetry in any organism) test explicitly for directional asymmetry. It is possible that directional asymmetry is a more common phenomenon than previously suspected.

Can directional asymmetry, as well as fluctuating asymmetry, indicate sensitivity to developmental perturbation? Most authors would probably argue that it cannot. The rationale for using fluctuating asymmetry as a measure of developmental stability is that it represents minor deviations from the bilateral plan when genotype and environment are the same for the left and right sides of the developing organism. However, there are cases in which the left and right sides of a developing organism do not experience the same environment. If the environmental stress has a directional component, all individuals would be subject to a similar influence; however, those individuals with less efficient developmental buffering (e.g., haploid males) might show a greater response to this pressure. Directional asymmetry in honey bees could have a proximal cause in the position of larvae, prepupae or pupae during development in nest cells (Jay, 1963a, b, 1964), though this hypothesis requires investigation.

The effects of hybridization on asymmetry and frequency of venation abnormalities were more complex. In diploid females the frequency of venation abnormalities is significantly greater in Nigra hybrids than in either subspecies, but mean asymmetry does not appear to be influenced by hybridization. These findings, along with the lack of correlation between asymmetry and abnormality for both females and males, imply that asymmetry and abnormality are independent responses to developmental disruption. In haploid males, both asymmetry and frequency of venation abnormalities are high in Nigra hybrids, but asymmetry is not significantly greater in Nigra than in mellifera, and mean number of venation abnormalities is not significantly greater in Nigra than in carnica.

Two explanations of these results must be considered. One alternative is that in this case, hybridization has no effect on developmental stability, whether or not it leads to disruption of coadapted gene complexes. Venation abnormalities and asymmetry could be inherited traits, probably with variable penetrance. The high frequency of venation abnormalities in Nigra males and females may simply reflect a high frequency of such alleles in that population. (But the high frequency of asymmetry in mellifera drones and venation abnormality in carnica drones would remain unexplained.) Expression or penetrance of these alleles could be higher in haploids than in diploids for a number of reasons, including the case where the alleles behave like recessives in diploids. This hypothesis could be tested using standard quantitative genetic techniques. The heritability of asymmetry and venation abnormalities could also be measured using artifically inseminated queens (e.g., Harbo, 1986). Such an analysis would test the relative importance of additive genetic effects and environment in causing asymmetry and abnormalities.

A second, more plausible alternative is that wing venation abnormalities are both heritable and indicators of developmental instability. The penetrance of these traits 
could be influenced by the individual's degree of developmental stability, which is influenced in turn by ploidy and hybridization. If the high frequency of venation abnormalities in Nigra and carnica males were simply due to high frequencies of alleles promoting venation abnormalities in these two populations, then we should see a high frequency of venation abnormalities in carnica females, too. The data presented here would imply a high frequency of alleles for venation abnormalities in the Nigra and carnica populations, with high penetrance in all haploid males and the hybrid females.

A third alternative is that our small sample of drones has given us misleading results. If all contrasts between the hybrid Nigra males and the carnica and mellifera males had been significant, it would have been simple to conclude that hybridization results in females who are able to suppress some types of developmental perturbation (asymmetry) and unable to suppress others (venation abnormalities), whether or not they have a heritable component. Haploid males would be less able to suppress either perturbation. It is possible that the smaller sample size for males (118 males vs. 261 females) simply made it more difficult to detect true differences between the populations from which the drone samples were drawn, but until a larger sample of drones can be examined, this must remain speculation.

Waddington $(1942,1957)$ developed the concept of developmental canalization to describe the result of natural selection for genotypes robust to environmental perturbation in their programming of a certain phenotype. There is a chain of assumptions in studies using fluctuating asymmetry as a measure of developmental stability. We ask, does treatment $X$ (hybridization, ploidy) have an effect on developmental stability? We compare treatments (haploid versus diploid, hybrid versus purebred), by measuring asymmetry or abnormalities or any other chosen character. We assume that if treatment $X$ does affect developmental stability, the effect will be reflected in the character we measure. However, if our measures reveal no effect, it could mean that $X$ has no effect on developmental stability, or that stability has been affected, but our measure does not detect it (as in the differing responses of asymmetry and venation abnormality to hybridization and ploidy). Thus we recommend the use of more than one measure of developmental perturbation. In light of our finding that directional asymmetry can be a major component of total asymmetry, we also recommend explicit testing for directional, as well as fluctuating, asymmetry.

\section{Conclusions}

Fluctuating asymmetry has often been considered an indicator of the degree of buffering against developmental perturbations. We investigated the effects of ploidy and inter-subspecies hybridization on asymmetry and wing venation abnormalities in honey bees, making use of a new method for the measurement of morphological asymmetry. This Procrustes method has general applicability and biological and statistical advantages over existing methods for the study of asymmetry. 
The measures of asymmetry in Palmer and Strobeck's (1986) survey of the literature of asymmetry measurement all refer to character values measured separately on left and right sides. The closest approach to our formula (1) in Palmer and Strobeck's (1986) table is their formula (9), the measure $\left(1-r^{2}\right)$, where $r$ is the correlation between left- and right-sided measures across a sample. When landmark locations are used in place of "characters," the richness of geometry supports an analogous quantity, our index $A^{2}$, for computation case by case. $A^{2}$ avoids the typical problems of multivariate morphometrics as reviewed by Palmer and Strobeck (1986) and Reyment et al. (1984) by comparing the two observations of the "same" landmark configuration in one direct measurement.

First, coverage of the form is as even as the pattern of landmarks itself. The problems of character sampling, and the character correlations endemic to computed distances and ratios, are completely circumvented. Furthermore, regardless of evenness of landmark pattern, the contributions of the separate landmarks to the net $A^{2}$ are weighted very nearly equally.

Second there is no ambiguity regarding "character size": only a single "size" applies to the analysis - centroid size, analogous to ordinary variance. Centroid size is a geometric size, in simple units of squared length. The value $A^{2}$, in turn, has a plain geometric meaning (Fig. 3) with no uncertainty as to its units: it is dimensionless.

Third, because the algebra underlying the measure $A^{2}$ is limited to sums of squares and cross-products, the comparison of directional and fluctuating asymmetry is itself just another partition of sums of squares, as we have demonstrated above. The technique also meets the conditions for comparing different samples via $F$-ratios, as recommended by Palmer and Strobeck (1986), although we do not demonstrate this extension here.

Application of this method to forewing asymmetry in male (haploid) and female (diploid) honey bees (Apis mellifera) gave unexpected results. As other authors have shown, haploid males showed higher total asymmetry (and higher frequency of venation abnormalities) than diploid females. However most of the difference in asymmetry between males and females was due to directional asymmetry, not fluctuating asymmetry. Since few studies of asymmetry test explicitly for directional asymmetry, it is possible that directional asymmetry is a more common phenomenon than previously suspected.

The effects of hybridization between the subspecies $A . \mathrm{m}$. mellifera and A. $\mathrm{m}$. carnica on asymmetry and frequency of abnormalities were more complex. In diploid females the frequency of venation abnormalities is significantly greater in a population of hybrid origin than in either subspecies, but mean asymmetry does not appear to be influenced by hybridization. In haploid males, both asymmetry and frequency of venation abnormalities are high in a population of hybrid origin, but asymmetry is not significantly greater in the hybrids than in mellifera, and mean number of venation abnormalities is not significantly greater in hybrids than in carnica. These findings, along with the lack of correlation between asymmetry and abnormality for both females and males, imply that asymmetry and abnormality are independent responses to developmental disruption. Thus in studies of fluctuat- 
ing asymmetry we recommend (1) the use of more than one measure of developmental perturbation, and (2) explicit testing for directional, as well as fluctuating, asymmetry.

\section{Acknowledgements}

We especially thank F. Ruttner, who suggested populations to sample and provided information on the history of $A . m$. mellifera, A. m. carnica and Nigra populations. We also thank N. and G. Koeniger, H. Pechhacker, S. Toft, H. Hansen, A. Hagen, A. Aarhus, I. Fries, and P. Pamilo for help in collecting specimens, and $\mathrm{W}$. Fink for use of his morphometric analysis system. Two anonymous reviewers made substantial contributions to the revision of this manuscript.

The bees sampled were from the apiaries of B. Stoklund, Laesø, Denmark; T. Gjessing, Billingstad, Norway; The Swedish University of Agricultural Sciences, Uppsala, Sweden; P. Lettenbichler, Ötztalbanhof, Austria; The Steirmarke Imkerschule, Graz, Austria; J. Humele, Villach, Austria; and H. Pechhacker, Lunz-am-See, Austria.

This work was supported by NSF grant BSR-87099661 to DRS, NSF grant BSR-8800185 to BJC, and USPHS grant GM37251 to FLB.

\section{References}

Adam, 1951. In search of the best strains of bees. Bee World 32: 49-52.

Adam, 1954. In search of the best strains of bee: second journey. Bee World 35: 193-203, 233-244.

Adam, 1961. The honey bees of the Iberian peninsula. Bee World 42: 252-255.

Adam, 1964. In search of the best strains of bee: concluding journeys. Bee World 45: 70-83, 104-118.

Adam, 1977. In search of the best strains of bees: supplementary journey to Asia Minor, 1973. Bee World 58: $57-66$

Alpatov, V. V. 1929. Biometrical studies on variation and the races of bees. Quart. Rev. Biol. 4: 1-58.

Auffray, J.-C., P. Alibert, S. Renaud and F. Bonhomme. 1996. Fluctuating asymmetry in Mus musculus subspecific hybridization: Traditional and Procrustes comparative approaches, pp 275-283. In L. F. Marcus, M. Corti, A. Loy, G. J. P. Naylor and D. E. Slice (Eds.), Advances in Morphometrics. NATO ASI Series A: Life Sciences, vol. 284, Plenum, NY.

Bookstein, F. L. 1991. Morphometric Techniques for Landmark Data. Cambridge University Press

Bookstein, F. L. 1995a. Metrics and symmetries of the morphometric synthesis, pp 139-153. In K. V. Mardia and C. A. Gill (Eds.), Proceedings in Current Issues in Statistical Shape Analysis. Leeds University Press.

Bookstein, F. L. 1995b. The Morphometric Synthesis for landmarks and edge-elements in images. Terra Nova 7: 393-407.

Bookstein, F. L. 1996a. Biometrics, biomathematics, and the morphometric synthesis. Bulletin of Mathematical Biology 58: 313-365.

Bookstein, F. L. 1996b. Combining the tools of geometric morphometrics, pp 131-152. In L. F. Marcus et al. (Eds.), Proceedings of the 1993 NATO ASI on Morphometrics. Plenum.

Brückner, D. 1976. The influence of genetic variability on wing symmetry in honeybees (Apis mellifera). Evolution 30: 100-108.

Bulfinch, T. 1991. Bulfinch's Mythology. HarperCollins Publishers, New York, NY.

Castecl, D. B. and E. F. Phillips. 1903. Comparative variability of drones and workers of the honey bee. Biol. Bull. 6: $18-37$.

Clarke, G. M., B. P. Oldroyd and P. Hunt. 1992. The genetic basis of developmental stability in Apis mellifera: heterozygosity versus genic balance. Evolution 46: 753-762. 
Cornuet, J.-M., A. Daoudi and C. Chevalet. 1986. Genetic pollution and number of matings in a black honey bee (Apis mellifera mellifera) population. Theor. Appl. Genet. 73: 223-227.

Cornuet, J.-M., J. Fresnaye and L. Tassencourt. 1975. Discrimination et classification de populations d'abeilles a partir de characteres biometrique. Apidologie 6: 145-187.

Eickwort, K. R. 1969. Differential variation of males and females in Polistes exclamens. Evolution 23: 391-405.

Ferguson, M. 1986. Developmental stability of rainbow trout hybrids: genomic coadaptation or heterozygosity? Evolution 40: 323-330.

Fink, W. L. 1987. Video digitizer: a system for systematic biologists. Curator 30: 63-72.

Geisel, T. and A. S. Geisel, 1960. One fish, two fish, red fish, blue fish, pp 20-21. Beginner Books, Inc., New York, NY.

Goodall, C. R. 1991. Procrustes methods in the statistical analysis of shape. Journal of the Royal Statistical Society B53: $285-339$.

Gower, J. C. 1975. Generalized Procrustes analysis. Psychometrika 40: 33-51.

Graham, J. H. and J. D. Felley. 1985. Genomic coadaptation and developmental stability within introgressed populations of Enneacanthus gloriosus and E. obesus (Pisces, Centrarchidae). Evolution 39: 104-114.

Hagen, R. H., D. R. Smith and S. W. Rissing, 1986. Genetic relatedness among co-foundresses of two desert ants, Veromessor pergandei and Acromyrmex versicolor (Hymenoptera: Formicidae). Psyche 95: 191-201.

Harbo, J. R. 1986. Propagation and instrumental insemination, pp 361-389. In T. E. Rinderer (Ed.), Bee Genetics and Breeding. Academic Press, Inc., N.Y.

Jackson, J. F. 1973. A search for the population asymmetry parameter. Syst. Zool. 22: 166-170.

Jay, S. C. 1963a. The development of honeybees in their cells. J. Apic. Reserch 117-134.

Jay, S. C. $1963 \mathrm{~b}$. The longitudinal orientation of larval honey bees (Apis mellifera) in their cells. Canadian Journal of Zoology 41: 717-723.

Jay, S. C. 1964. The cocoon of the honey bee, Apis mellifera L. Canad. Ent. 96: 784-792.

Lamb, T. and J. C. Avise. 1987. Morphological variability in genetically defined categories of anuran hybrids. Evolution 41: 157-165.

Leary, R. F., F. W. Allendorf and K. L. Knudsen. 1983. Developmental stability and enzyme heterozygosity in rainbow trout. Nature 301: 71-72.

Leary, R. F., F. W. Allendorf and K. L. Knudsen. 1984. Superior developmental stability of heterozygotes at enzyme loci in salmonid fishes. Amer. Nat. 124: 540-551.

Leary, R. F., F. W. Allendorf, K. L. Knudsen and G. H. Thorgaard. 1985. Heterozygosity and developmental stability in gynogenetic diploid and triploid rainbow trout. Heredity 54: 219-225.

Lerner, I. M. 1954. Genetic Homeostasis. Wiley, N.Y.

Marcus, L. F., E. Bello and A. García-Valdecasas (Eds.). 1993. Contributions to Morphometrics. Madrid: Monografias, Museo Nacional de Ciencias Naturales, Consejo Superior de Investigaciones Cientificas.

Marcus, L. F., M. Corti, A. Loy, G. Naylor and D. Slice (Eds.). 1996. Advances in Morphometrics: Proceedings of the 1993 NATO ASI on Morphometrics. New York: Plenum.

Mardia, K. V. and C. A. Gill (Eds.). 1995. Proceedings in Current Issues in Statistical Shape Analysis. Leeds University Press.

McKenzie, J. A. and G. M. Clarke. 1988. Diazinon resistance, fluctuating asymmetry and fitness in the Australian sheep blowfly, Lucilia cuprina. Genetics 120: 213-220.

Owen, R. E. 1989. Differential size variation of male and female bumblebees. J. Heredity 80: 39-43.

Palmer, A. R. and C. Strobeck. 1986. Fluctuating asymmetry: measurement, analysis, pattern. Ann. Rev. Ecol. Syst. 17: $391-421$.

Reyment, R. A., R. E. Blackith and N. A. Campbell. 1984. Multivariate Morphometrics (2nd ed.), Academic Press, New York, NY.

Richardson, B. J., P. R. Baverstock and M. Adams. 1986. Allozyme electrophoresis. Academic Press, Sydney. 
Rohlf, F. J. 1990. Rotational fit (Procrustes) methods, pp 227-236. In F. J. Rohlf and F. L. Bookstein (Eds.), Proceedings of the Michigan Morphometrics Workshop, University of Michigan Museum of Zoology.

Rohlf, F. J. 1993. Relative warp analysis and an example of its application to mosquito wings, pp 131-159. In L. Marcus et al. (Eds.), Contributions to Morphometrics. Monografias, Museo Nacional de Ciencias Naturales, Consejo Superior de Investigaciones Cientificas, Madrid, 1993.

Rohlf, F. J. and D. Slice, 1990. Extensions of the Procrustes method for the optimal superposition of landmarks. Systematic Zoology 39: 40-59.

Ross, K. G. and J. L. Robertson. 1990. Developmental stability, heterozygosity, and fitness in two introduced fire ants (Solenopsis invicta and S. richteri) and their hybrid. Heredity 64: 93-104.

Ruttner, F. 1968. Les races d'abeilles, pp 27-44. In R. Chauvin (Ed.), Traite de Biologie de L'abeille, Tome I, Biologie et Physiologie Generales. Masson et Cie., Paris.

Ruttner, F. 1988. Biogeography and Taxonomy of Honeybees. Springer-Verlag, New York.

Ruttner, F., L. Tassencourt and J. Louveaux. 1978. Biometrical-statistical analysis of the geographic variability of $A$. mellifera $\mathrm{L}$. Apidologie 9: 363-381.

Siegel, A. F. and R. H. Benson. 1982. A robust comparison of biological shapes. Biometrics 38: $341-350$.

Sheppard, W. S. and S. H. Berlocher. 1984. Enzyme polymorphism in Apis mellifera from Norway. J. Apic. Res. 23: 64-69.

Sheppard, W. S. and S. H. Berlocher. 1985. New allozyme variability in Italian honey bees. J. Hered. 76: $45-48$.

Sheppard, W. S. and B. A. McPhcron. 1986. Genetic variation in honey bees from an area of racial hybridization in western Czechoslovakia. Apidologie 17: 21-32.

Smith, D. R. 1988. Mitochondrial DNA polymorphisms in five Old World subspecies of honey bees and in New World hybrids, pp 303-312. In G. R. Needham, R. E. Page Jr., M. Delfinado-Baker and C. Bowman (Eds.), Africanized Honey Bees and Bee Mites. Ellis Horwood Ltd. Chichester, New York.

Smith, D. R. and W. M. Brown. 1990. Restriction endonuclease cleavage site and length polymorphisms in mitochondrial DNA of Apis mellifera mellifera and A. m. carnica (Hymenoptera: Apidae). Ann. Entomol. Soc. Amer. 83: 81-88.

Smith, D. R., O. R. Taylor and W. M. Brown. 1989. Neotropical Africanized honeybees have African mitochondrial DNA. Nature 339: 213-215.

Sylvester, H. A. 1982. Electrophoretic identification of Africanized honeybees. Journal of Apicultural Research 21(2): 93-97.

Vrijenhoek, R. C. and S. Lehrman. 1982. Heterozygosity and developmental stability under sexual and asexual breeding systems. Evolution 36: 768-776.

Waddington, C. H. 1942. Canalization of development and the inheritance of acquired characters. Nature 150: $563-565$.

Waddington, C. H. 1957. The strategy of the genes. George Allen Unwin, London.

Wayne, R. K., W. S. Modi and S. J. O'Brien. 1989. Morphological variability and asymmetry in the cheetah (Acinonyx jubatus), a genetically uniform species. Evolution 40: 78-85.

Received 30 July 1996 ;

revised 12 November 1996;

accepted 20 December 1996. 